\title{
Global biogeophysical interactions between forest and climate
}

\author{
Victor Brovkin, ${ }^{1}$ Thomas Raddatz, ${ }^{1}$ Christian H. Reick, ${ }^{1}$ Martin Claussen, ${ }^{1,2}$ and \\ Veronika Gayler ${ }^{1}$ \\ Received 30 January 2009; revised 6 March 2009; accepted 11 March 2009; published 9 April 2009.
}

[1] In two sensitivity experiments using the Earth System Model of the Max Planck Institute for Meteorology (MPIESM), the vegetation cover of the ice-free land surface has been set worldwide to either forest or grassland in order to quantify the quasi-equilibrium response of the atmosphere and ocean components to extreme land surface boundary conditions. After 400 years of model integration, the global mean annual surface temperature increased by $0.7^{\circ} \mathrm{K}$ and declined by $0.6^{\circ} \mathrm{K}$ in the forest and grassland simulations, respectively, as compared to the control simulation. Thereafter, the geographic distribution of vegetation has been allowed to respond interactively to climate. After subsequent 500 years of interactive climate-vegetation dynamics, both forest and grassland simulations converged to essentially the same climate state as in the control simulation. This convergence suggests an absence of multiple climate-forest states in the current version of the MPI-ESM. Citation: Brovkin, V., T. Raddatz, C. H. Reick, M. Claussen, and V. Gayler (2009), Global biogeophysical interactions between forest and climate, Geophys. Res. Lett., 36, L07405, doi:10.1029/2009GL037543.

\section{Introduction}

[2] The terrestrial biosphere is an important dynamic component of the climate system. In particular, forest cover has a significant effect on climate through biogeophysical effects [e.g., Bonan, 2008; Claussen et al., 2004]: a dense forest canopy has a lower albedo than grass, so that forest canopies trap more irradiation. This effect is extremely pronounced in the presence of snow. Additionally, during the growth season, trees transpire more water than herbaceous plants. The cooling effect of forests via enhanced transpiration counteracts the warming effect due to the decrease in albedo.

[3] The biogeophysical effects of large-scale changes in vegetation cover on climate have been studied by a wide spectrum of climate models of different complexity. Simulations of climate models of intermediate [Ganopolski et al., 2001; Renssen et al., 2003] and full complexity [e.g., Pitman and Zhao, 2000] where alteration of global climate through oceanic and cryospheric feedbacks was included, demonstrated that the effect of boreal forests on climate can be strongly amplified through the sea ice - albedo feedback, while the climate response to tropical deforestation is more equivocal. Brovkin et al. [2006] showed that interac-

\footnotetext{
${ }^{1}$ Max Planck Institute for Meteorology, Hamburg, Germany.

${ }^{2}$ Also at KlimaCampus, University of Hamburg, Hamburg, Germany.
}

Copyright 2009 by the American Geophysical Union. 0094-8276/09/2009GL037543 tive ocean and sea ice dynamics modify the effect of historical land cover change on northern hemisphere climate significantly.

[4] Changes in forest cover also affect the global carbon cycle. Model studies suggest that the net effect of deforestation is a cooling for boreal and a warming for tropical regions [Bala et al., 2007; Betts, 2000; Claussen et al., 2001]. This study focuses on biogeophysical interactions between forest cover and climate. Accordingly, the atmospheric $\mathrm{CO}_{2}$ concentration is kept fixed, i.e. the biogeochemical effect of forest on climate is not included.

[5] Since forest cover modifies climate and vice versa, a valid question is whether the positive feedback between climate and forests is strong enough to support different states (or climate regimes) depending on the initial conditions. Earlier modeling studies [Brovkin et al., 2003; Claussen, 1998; Levis et al., 1999] found only one state in the climate system in the northern high latitudes. Oyama and Nobre [2003] found a possibility for a new climatevegetation equilibrium state in the Amazon. In the present study, we test the possibility of multiple states in the climate system by carrying out transient simulations with interactive vegetation starting from different initial conditions: worldwide forest or grassland cover, respectively. Another interesting question addressed here is whether the forested Earth is warmer or cooler than the Earth covered by grasses. Kleidon et al. [2000] came to conclusion that the forest world is cooler than the present-day climate, however, their study was performed with prescribed SSTs and sea ice. Fraedrich et al. [2005] included the response of a mixedlayer ocean and a thermodynamic sea-ice model and found that the forest planet is warmer than the present-day climate. Gibbard et al. [2005] used an atmospheric general circulation model coupled to a slab ocean model and found that global replacement of current vegetation by trees or grass would lead to a global mean warming of $1.3^{\circ} \mathrm{C}$ or cooling of $0.4^{\circ} \mathrm{C}$, respectively. Our simulations constitute an additional step forward since we account for the response of the thermohaline circulation to changes in the forest cover.

\section{Methods}

[6] We used the Earth System model developed at the Max Planck Institute for Meteorology in Hamburg, Germany (MPI-ESM). It includes the atmospheric model ECHAM5 at T31 $\left(3.8^{\circ} \times 3.8^{\circ}\right)$ resolution with 19 vertical levels, the oceanic model MPI-OM at approx. $3^{\circ}$ resolution with 40 vertical layers [Jungclaus et al., 2006], and the land surface model JSBACH [Raddatz et al., 2007]. All modules interact directly without flux adjustments.

[7] The JSBACH model simulates fluxes of energy, water, momentum, and $\mathrm{CO}_{2}$ between land and atmosphere. The modelling concept is based on a tiled (fractional) 
structure of the land surface. Each land grid cell is divided into tiles covered with 8 plant functional types or PFTs (trees, shrubs, and grasses), 2 types of bare surface (seasonally bare soil and permanently bare ground, i.e. desert), and tiles with land cover excluded from natural vegetation dynamics (inland water, crops, etc., not used in this study).

\subsection{Dynamic Vegetation Module}

[8] The JSBACH model has been recently updated with an efficient module for vegetation dynamics. It is based on the assumption that competition between different PFTs is determined by their relative competitiveness expressed in annual net primary productivity (NPP), as well as natural and disturbance-driven mortality. This approach reflects the importance of the balance between extinction-immigration (i.e. establishment and mortality) and competitive strengths in accordance with meta-populations concepts [Hanski, 1998]. NPP is used as a measure of competitiveness because the productivity or relative growth rates are in general linked to competitiveness at the short term [e.g., Berendse, 1994]. At the long term, the competitiveness is determined by the plant life span, which is also accounted for in our approach.

[9] The dynamics of the fraction $f_{i}$ of the area covered by a plant functional type $i, \mathrm{PFT}_{i}$, is governed by the following equation:

$$
\frac{d f_{i}}{d t}=E\left(f_{i}\right)-M\left(f_{i}\right)-D\left(f_{i}\right)
$$

where $E, M$, and $D$ are establishment, natural, and disturbance-driven mortality terms, respectively.

[10] The establishment term $E\left(f_{i}\right)$ for woody $\mathrm{PFT}_{i}$ is calculated from annual NPP, $N_{i}$, the establishment time scale, $\tau_{i}^{\text {est }}$, and from the $\mathrm{PFT}_{i}$ fraction $f_{i}$ :

$$
E\left(f_{i}\right)=\mu(\vec{f}) \frac{\left(N_{i}\right)^{\alpha} \cdot f_{i}}{\tau_{i}^{\text {est }} \sum_{\text {woody } P F T}\left(N_{k}\right)^{\alpha} f_{k}}, \quad \vec{f}=\left(f_{1}, f_{2}, \ldots\right),
$$

where the factor $\alpha$ suppresses establishment for small NPP ( $\alpha$ is taken as 1.5 to keep the non-linearity moderate). The function $\mu(\vec{f})$ accounts for limitations in the area available for establishment, $1-\sum_{\text {all } P F T} f_{k}$. The function $\mu \vec{f}$ is equal to 1 if there is enough area for establishment, while it declines rapidly to zero if the available area is less than a certain threshold.

[11] Only woody PFTs which i) are within bioclimatic limits for establishment based on parameterization by Sitch et al. [2003] and ii) have positive NPP in the given year are accounted for in the equation (2). The equation for establishment of herbaceous PFTs is similar to the equation (2) with the assumption that grass can establish only within the area left available after tree establishment, similar to the approach by Sitch et al. [2003]. Consequently, woody PFTs are assumed to have an advantage over grasses in the absence of disturbances such as fires.

[12] Natural mortality $M\left(f_{i}\right)$ is formulated as linear decay

$$
M\left(f_{i}\right)=\frac{f_{i}}{\tau_{i}^{l i f e}},
$$

where $\tau_{i}^{\text {life }}$ is the average life span of the $\mathrm{PFT}_{i}$. Disturbance mortality $D\left(f_{i}\right)$ includes mortality due to fire and wind disturbances. To simulate the litter flammability, the fire disturbance is a function of relative humidity of the lowest atmosphere layer, which is used as an indicator for litter moisture and includes a threshold in litter biomass. This parameterization limits tree encroachment in dry continental regions. The wind disturbance reflects the reduction in forest cover by storms, and is parameterized by a function of daily maximum $10 \mathrm{~m}$ wind speed.

[13] The equations $(1-3)$ are an extension to the existing non-dynamic vegetation model JSBACH with carbon cycle [Raddatz et al., 2007]. In the long-term they result in competitive extinction of PFTs with low NPP in the absence of disturbances. However, since disturbances are always present in ecosystems, the equilibrium is shifted towards PFTs that can quickly recover from the disturbances, such as grasses. Accounting for disturbances is important, because on the long-term ecosystem composition is driven by the re-establishment ability [e.g., Lavorel and Garnier, 2002].

[14] Comparison of the simulated tree cover with satellitebased observations is presented in Figure 1. The fractional estimates of tree cover from the Vegetation Continuous Fields data collection [Hansen et al., 2007] were averaged on the grid of the MPI-ESM. As present-day tree cover is heavily reduced by anthropogenic deforestation, the natural tree cover simulated by our model has been corrected with crop data in accordance to landuse reconstruction by Pongratz et al. [2008]. Comparison of the observed and simulated tree fraction shows that the model performance is far from being perfect; however, the main patterns of boreal and temperate forests are well reproduced. In general, the model overestimates the forest cover, partly due to climate biases of the atmosphere model (eastern Brazil, South Africa) and partly due to a tendency of the vegetation model to simulate tree encroachment in dry regions (central Eurasia) where disturbances are underestimated. The correlation coefficient between the simulated and the observed tree cover is 0.68 .

\subsection{Experiment Setup}

[15] Three simulations have been performed using the MPI-ESM. The CTRL simulation had no changes in land surface conditions. In the TREE experiment, $100 \%$ tree cover was prescribed in every land grid cell; the tree PFTs were chosen on the basis of the CTRL simulation. The model has been run for 400 years with interactive atmosphere and ocean to achieve a state close to equilibrium. Subsequently, the simulation has been continued for 500years with interactive vegetation cover. Simulation GRASS has been performed with vegetation cover prescribed to grass everywhere during the first 400 years and interactive vegetation thereafter.

\section{Results}

[16] In the TREE simulation, global mean surface temperature increases by $0.7^{\circ} \mathrm{C}$ after 400 years with prescribed forest cover. Averaged land surface temperature increases by $1.2^{\circ} \mathrm{C}$. This warming is mainly caused by a decrease in albedo by $0.1-0.3$ in the northern high latitude regions 

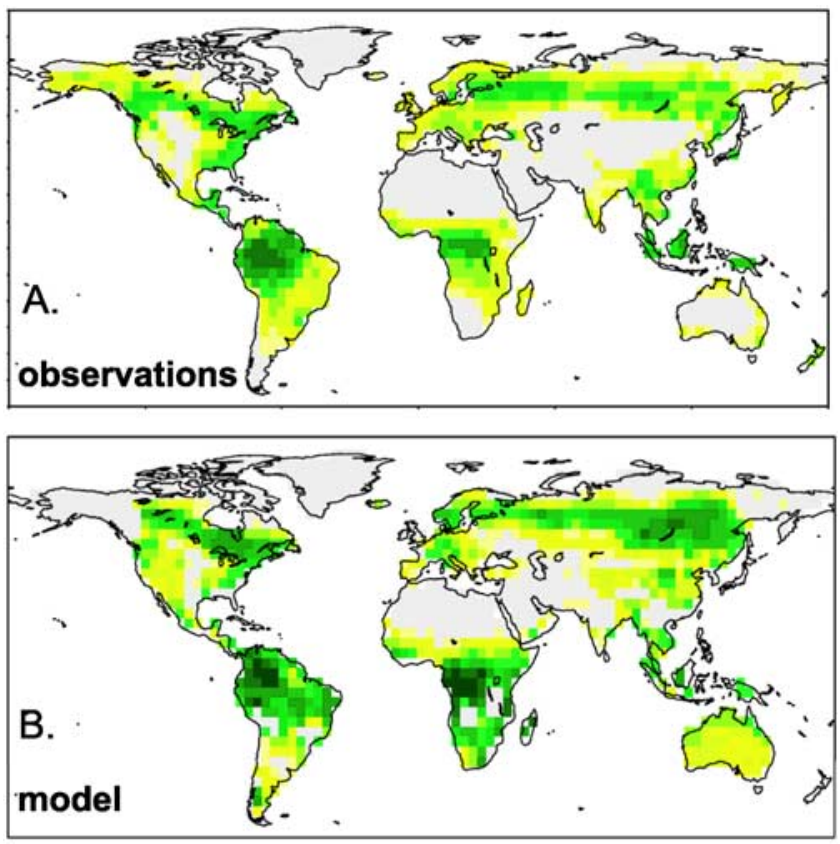

$\begin{array}{llllllllll}0.05 & 0.1 & 0.2 & 0.3 & 0.4 & 0.5 & 0.6 & 0.7 & 0.8 & 0.9\end{array}$

Figure 1. (a) Present-day tree cover based on MODIS data [Hansen et al., 2007] averaged on the MPI-ESM grid. (b) Natural tree cover in the control simulation (modified to account for historical deforestation).

with snow cover in the CTRL simulation. Most of the warming occurs in the northern polar regions during winter (Figure 2a), mainly due to a loss of sea ice cover and a warming of the ocean surface. In the northern North
Atlantic, the SST decreases in response to a reduction of the Atlantic meridional overturning circulation (MOC) at $30^{\circ} \mathrm{N}$ from 15.6 to $12 \mathrm{~Sv}$. In boreal summer, the warming in the northern high latitudes is not as pronounced as in winter (Figure 2b). Summer temperatures over the North Africa and desert regions in the middle Asia increase by $1-4^{\circ} \mathrm{C}$.

[17] In the GRASS simulation, temperatures go down by $2-4^{\circ} \mathrm{C}$ over most of the northern hemisphere continents during both winter and summer seasons (Figures $2 \mathrm{c}$ and $2 \mathrm{~d}$ ). This is mainly a response to the albedo increase of the deforested areas. In contrast, deforested tropical forest regions show an increase in temperature due to reduced transpiration. This is especially valid for the western Amazon region where the temperature increases by up to $5^{\circ} \mathrm{C}$. Overall, the surface temperature declines by $0.6^{\circ} \mathrm{C}$ and $0.8^{\circ} \mathrm{C}$ for global and land averages, respectively. This global cooling is in particular due to the response of sea ice and SST, which is pronounced in the Arctic region during winter. Atlantic $\mathrm{MOC}$ at $30^{\circ} \mathrm{N}$ increases from 15.6 to $17.7 \mathrm{~Sv}$.

[18] Changes in annual precipitation are shown in Figure 3. The TREE simulation produces in general more precipitation over land than the CTRL simulation (Figure 3a). In particular, rainfall increases strongly over monsoon regions in North Africa, Asia and East Asia. In contrast, the weakening of the Atlantic MOC leads to less precipitation over the northern North Atlantic and to a slightly drier climate in Western Europe. The GRASS simulation is drier in most regions, especially in the tropical areas where massive deforestation leads to a substantial reduction of moisture recycling.

[19] The time evolution of global mean surface temperature is shown in Figure 4. In response to the instantaneous increase in forest cover at the beginning of the TREE simulation, temperature increases rapidly by about $0.5^{\circ} \mathrm{C}$ with a slow warming trend thereafter. In the GRASS

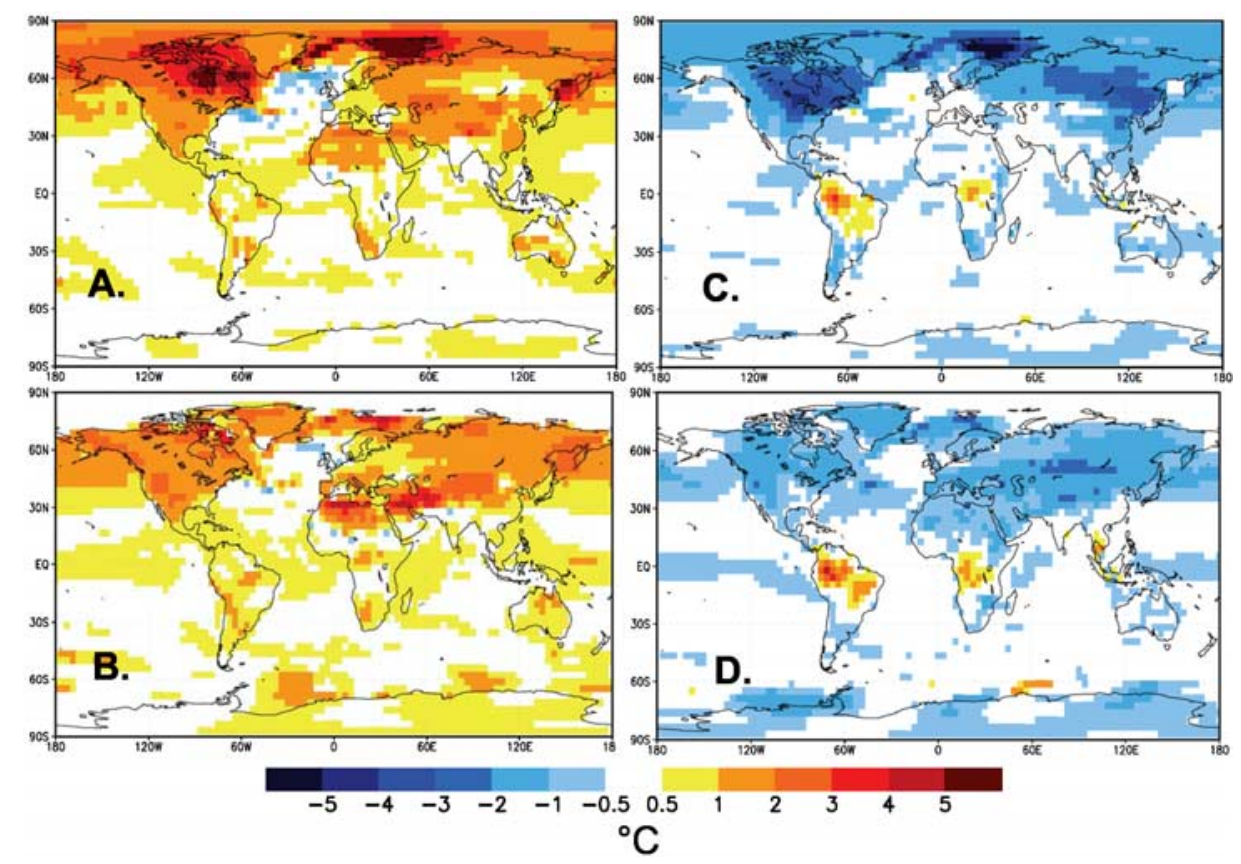

Figure 2. Changes in seasonal mean surface temperature $\left({ }^{\circ} \mathrm{K}\right)$ relative to the CTRL simulation: (a) TREE simulation, DJF, (b) TREE simulation, JJA, (c) GRASS simulation, DJF, and (d) GRASS simulation, JJA. Shown are changes at 95\% statistical significance level averaged over the last 100 years from the 400 -yr run with fixed vegetation cover. 


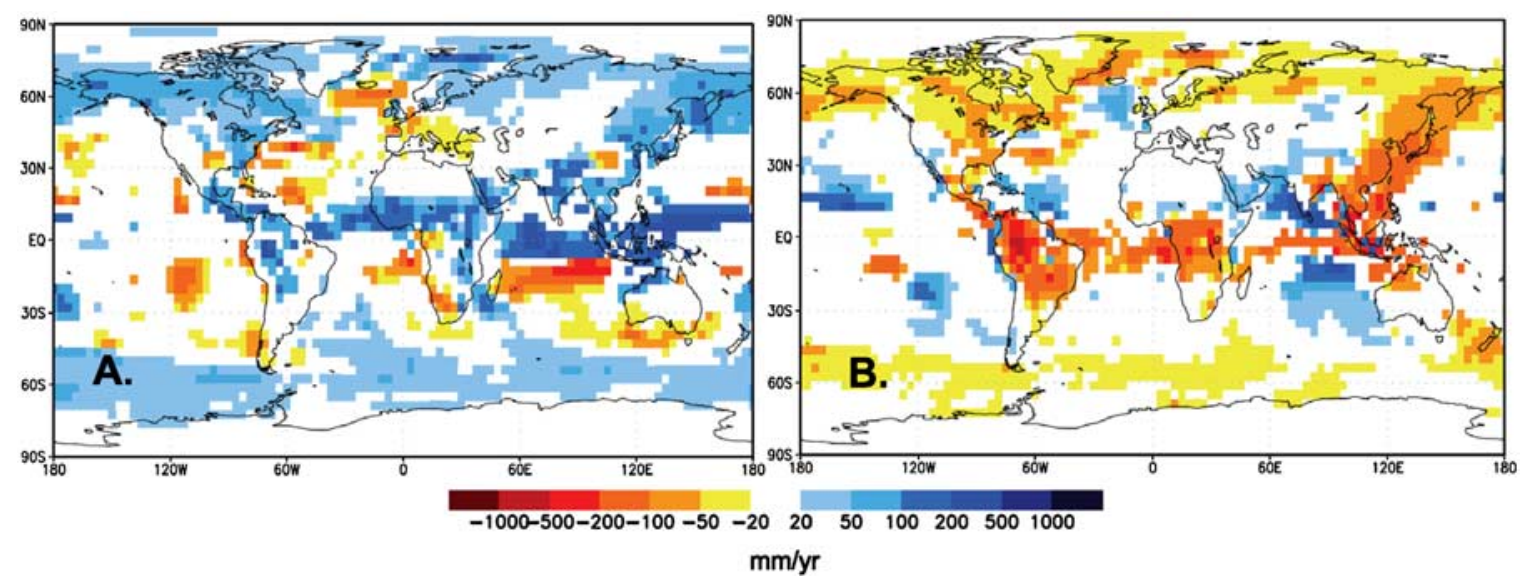

Figure 3. Changes in annual mean precipitation ( $\mathrm{mm} / \mathrm{yr}$ ) relative to the CTRL simulation: (a) TREE simulation and (b) GRASS simulation. Shown are changes at $95 \%$ statistical significance level averaged over the last 100 of the 400 -yr run with fixed vegetation cover.

simulation, the temperature change during the first 100 years is not as abrupt as in the TREE simulation. After 300 to 400 years of model integration, the global mean annual surface temperature increases by $0.7^{\circ} \mathrm{K}$ and declines by $0.6^{\circ} \mathrm{K}$ in the TREE and GRASS simulations, respectively, Thereafter, the vegetation cover is allowed to respond interactively to climate. After consequent 500 years of interactive climate-vegetation dynamics, both tree and grass simulations converge to essentially the same climate and forest state as in the control simulation (see Figure $\mathrm{S}^{1}{ }^{1}$ ). This convergence suggests the absence of multiple climateforest states in the current version of the MPI-ESM.

\section{Discussion and Conclusions}

[20] This is one of the first simulations of a forest and a grass planet using a state-of-the-art Earth System model that includes a dynamic ocean model. The forest planet is warmer by $0.7^{\circ} \mathrm{K}$ and the grass planet is cooler by $0.6^{\circ} \mathrm{K}$ in comparison with climate for present-day vegetation cover. The warming effect of global afforestation is less than $1.3^{\circ} \mathrm{C}$ found in simulations by Gibbard et al. [2005]. This could be explained by a relatively higher tree cover in our control simulation due to a usage of dynamic vegetation model. Besides, a reduction of Atlantic MOC counteracts to a warming caused by global afforestation. This may lead to overestimation of warming in simulations with the slab ocean models [e.g., Brovkin et al., 2003].

[21] Our results corroborate the significant ability of vegetation cover to alter the Earth climate through biogeophysical feedbacks. In particular, the northward treeline shift by greenhouse-induced warming can substantially amplify climate change in high northern latitudes. Our simulations starting from different initial conditions suggest that the MPI-ESM in its current version does not possess multiple climate-forest states.

[22] There are limitations of the experiment setup. In particular, the JSBACH model does not include a module

\footnotetext{
${ }^{1}$ Auxiliary materials are available in the HTML. doi:10.1029/ 2009GL037543.
}

for pedogenesis and hence, for albedo changes caused by changes in soils. Albedo of bare ground is prescribed in accordance to present-day observations, and leaf area index is calculated based on climate conditions and NPP. When vegetation is prescribed in regions with unfavorable conditions for plant growth, the leaf area index is small and the calculated surface albedo is still dominated by the unchanged albedo of bare ground as compared to the CTRL simulation. This is not necessarily correct because even in the presence of sparse vegetation the background soil albedo can be lower because of carbon input from plant litter. This process could substantially modulate a climatic effect of vegetation cover in desert and semidesert environment.

[23] As an additional limitation, the biogeochemical effects of vegetation cover changes were not accounted for. A related issue pertains to the time scale of analysis: on centennial to millennial time scale the ocean biogeo-

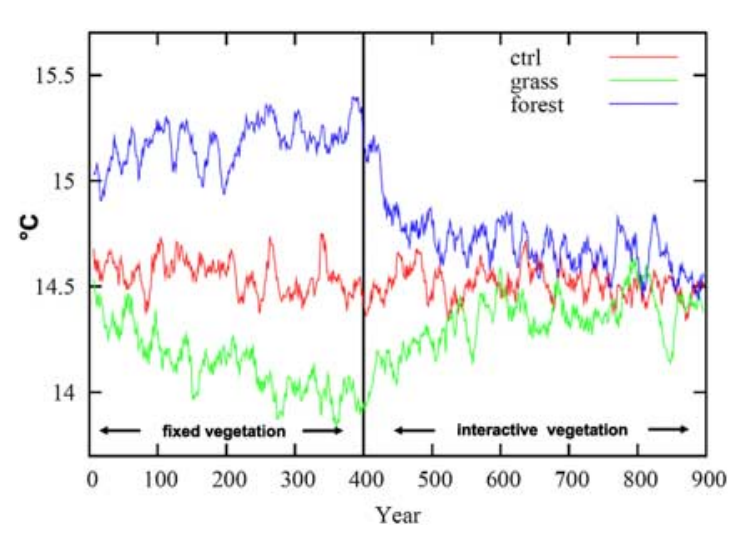

Figure 4. Dynamics of 10-yr averaged global surface temperature, ${ }^{\circ} \mathrm{C}$, in CTRL (red), GRASS (green), and TREE (blue) simulations. In TREE and GRASS simulations, vegetation cover was fixed to complete tree or grass cover in the model year 0 and kept constant for 400 years. After the year 400 , the vegetation cover responded interactively to climate. 
chemistry buffers most of the atmospheric $\mathrm{CO}_{2}$ changes induced by an altered land cover. This is a subject for further studies.

[24] Acknowledgments. The authors are grateful to Peter van Bodegom, Zhengyu Liu, and an anonymous reviewer for constructive and helpful comments on the manuscript. The simulations were performed at the German Climate Computing Center.

\section{References}

Bala, G., K. Caldeira, M. Wickett, T. J. Phillips, D. B. Lobell, C. Delire, and A. Mirin (2007), Combined climate and carbon-cycle effects of largescale deforestation, Proc. Natl. Acad. Sci. U. S. A., 104, 9911-9911.

Berendse, F. (1994), Competition between plant-populations at low and high nutrient supplies, Oikos, 71, 253-260.

Betts, R. A. (2000), Offset of the potential carbon sink from boreal forestation by decreases in surface albedo, Nature, 408, 187-190.

Bonan, G. B. (2008), Forests and climate change: Forcings, feedbacks, and the climate benefits of forests, Science, 320, 1444-1449.

Brovkin, V., S. Levis, M. F. Loutre, M. Crucifix, M. Claussen, A. Ganopolski, C. Kubatzki, and V. Petoukhov (2003), Stability analysis of the climatevegetation system in the northern high latitudes, Clim. Change, 57, 119138.

Brovkin, V., et al. (2006), Biogeophysical effects of historical land cover changes simulated by six Earth system models of intermediate complexity, Clim. Dyn., 26, 587-600.

Claussen, M. (1998), On multiple solutions of the atmosphere-vegetation system in present-day climate, Global Change Biol., 4, 549-559.

Claussen, M., V. Brovkin, and A. Ganopolski (2001), Biogeophysical versus biogeochemical feedbacks of large-scale land cover change, Geophys. Res. Lett., 28, 1011-1014.

Claussen, M., et al. (2004), Does land surface matter in climate and weather?, in Vegetation, Water, Humans and the Climate, Part A, edited by P. Kabat et al., Springer, Heidelberg.

Fraedrich, K., H. Jansen, E. Kirk, and F. Lunkeit (2005), The Planet Simulator: Green planet and desert world, Meteorol. Z., 14, 305-314.

Ganopolski, A., V. Petoukhov, S. Rahmstorf, V. Brovkin, M. Claussen, A. Eliseev, and C. Kubatzki (2001), CLIMBER-2: A climate system model of intermediate complexity. Part II: Model sensitivity, Clim. Dyn., 17, 735-751.
Gibbard, S., K. Caldeira, G. Bala, T. J. Phillips, and M. Wickett (2005), Climate effects of global land cover change, Geophys. Res. Lett., 32, L23705, doi:10.1029/2005GL024550.

Hansen, M., R. DeFries, J. R. Townshend, M. Carroll, C. Dimiceli, and R. Sohlberg (2007), 2001 Percent Tree Cover, Collection 4, Vegetation Continuous Fields MOD44B, http://glcf.umiacs.umd.edu/data/vcf/, Univ. of Md., College Park.

Hanski, I. (1998), Metapopulation dynamics, Nature, 396, 41-49.

Jungclaus, J. H., N. Keenlyside, M. Botzet, H. Haak, J. J. Luo, M. Latif, J. Marotzke, U. Mikolajewicz, and E. Roeckner (2006), Ocean circulation and tropical variability in the coupled model ECHAM5/MPI-OM, J. Clim., 19, 3952-3972.

Kleidon, A., K. Fraedrich, and M. Heimann (2000), A green planet versus a desert world: Estimating the maximum effect of vegetation on the land surface climate, Clim. Change, 44, 471-493.

Lavorel, S., and E. Garnier (2002), Predicting changes in community composition and ecosystem functioning from plant traits: Revisiting the Holy Grail, Funct. Ecol., 16, 545-556.

Levis, S., J. A. Foley, V. Brovkin, and D. Pollard (1999), On the stability of the high-latitude climate-vegetation system in a coupled atmosphere-biosphere model, Global Ecol. Biogeogr., 8, 489-500.

Oyama, M. D., and C. A. Nobre (2003), A new climate-vegetation equilibrium state for tropical South America, Geophys. Res. Lett., $30(23)$, 2199, doi:10.1029/2003GL018600.

Pitman, A. J., and M. Zhao (2000), The relative impact of observed change in land cover and carbon dioxide as simulated by a climate model, Geophys. Res. Lett., 27, 1267-1270.

Pongratz, J., C. Reick, T. Raddatz, and M. Claussen (2008), A reconstruction of global agricultural areas and land cover for the last millennium, Global Biogeochem. Cycles, 22, GB3018, doi:10.1029/2007GB003153.

Raddatz, T. J., C. H. Reick, W. Knorr, J. Kattge, E. Roeckner, R. Schnur, K. G. Schnitzler, P. Wetzel, and J. Jungclaus (2007), Will the tropical land biosphere dominate the climate-carbon cycle feedback during the twentyfirst century?, Clim. Dyn., 29, 565-574.

Renssen, H., H. Goosse, and T. Fichefet (2003), On the non-linear response of the ocean thermohaline circulation to global deforestation, Geophys. Res. Lett., 30(2), 1061, doi:10.1029/2002GL016155.

Sitch, S., et al. (2003), Evaluation of ecosystem dynamics, plant geography and terrestrial carbon cycling in the LPJ dynamic global vegetation model, Global Change Biol., 9, 161-185.

V. Brovkin, M. Claussen, V. Gayler, T. Raddatz, and C. H. Reick, Max Planck Institute for Meteorology, Bundesstrasse 55, D-20146 Hamburg, Germany. (victor.brovkin@zmaw.de) 